\title{
HPLC Method for Simultaneous Determination of Metronidazole and Preservatives in Vaginal Gel Formulation
}

\author{
Vania Maslarska $^{1}$, Boyka Tsvetkova ${ }^{2}$, Lily Peikova $^{2}$ and Stanislav Bozhanov ${ }^{{ }^{*}}$ \\ ${ }^{1}$ Medical University of Sofia, Faculty of Pharmacy, Department of Chemistry, 1000 Sofia, Bulgaria \\ ${ }^{2}$ Medical University of Sofia, Faculty of Pharmacy, Department of Pharmaceutical Chemistry, 1000 Sofia, Bulgaria
}

Received: 11 August 2016; accepted: 29 December 2016

\begin{abstract}
A high-performance liquid chromatography (HPLC) method with ultraviolet (UV) detection for simultaneous determination of metronidazole, methylparaben, and propylparaben in vaginal gel formulation was described. The chromatography was carried out on a $\mathrm{C}_{18}(250 \mathrm{~mm} \times 4.6 \mathrm{~mm}, 5 \mu \mathrm{m})$ column with acetonitrile and $0.3 \%$ phosphoric acid solution $(20: 80 \mathrm{v} / \mathrm{v})$ modified by $0.1 \%$ triethylamine as mobile phase, at a flow rate of $1.0 \mathrm{~mL} \mathrm{~min}{ }^{-1}$, with detection at $260 \mathrm{~nm}$. Under these chromatographic conditions, the obtained retention times were approximately $3.43 \mathrm{~min}$ for metronidazole, $5.17 \mathrm{~min}$ for propylparaben, and $15.12 \mathrm{~min}$ for methylparaben.

Analytical parameters specificity, linearity, accuracy, and precision were determined by validation procedure and found to be satisfactory. Overall, the proposed method was found to be simple, precise, and accurate for quality control of metronidazole in the presence of preservatives in gel formulation.
\end{abstract}

Keywords: Liquid chromatography, metronidazole, methylparaben, propylparaben, validation, vaginal gel

\section{Introduction}

Metronidazole (2-methyl-5-nitroimidazole-1-ethanol, MET) is classified therapeutically as an antibacterial and antiprotozoal agent, indicated for the treatment of bacterial vaginosis [1]. For the treatment of vaginitis, local administration of MET has been favored due to numerous side effects, toxicity, and teratogenic potential of the systematically applied drugs [2]. Several types of analytical procedures have been proposed for the analysis of MET in pharmaceutical formulations. The procedures include ultraviolet (UV) spectrophotometry [3-8], high-performance liquid chromatography (HPLC) [9-12], capillary zone electrophoresis [13], and electroanalytical techniques [14-31]. Parabens are a group of the alkyl esters of $p$-hydroxybenzoic acid. Methyl 4hydroxybenzoate (methylparaben, MP) and propyl 4-hydroxybenzoate (propylparaben, PP) are well-known preservatives used for decades as antimicrobial agents in pharmaceuticals, cosmetics, and food. Widespread use of parabens leads to their distribution in the environment, but the main pathway to penetrating the human body is usage of personal care products and medications. Although parabens are classified as safe, some studies suggested their skin irritation action, endocrine disrupting potential, and possible participation in the process of carcinogenesis [32]. Thus, the determination of these substances in pharmaceuticals and cosmetics is an important analytical task regarding quality control and safety. Some methods of analysis of investigated parabens either alone or in combination formulations are available, including HPLC [33-36], UV spectrophotometry [37], and micellar electrokinetic chromatography [38]. Simultaneous determination of both parabens and MET in suspesions is described by using HPLC procedures [39, 40]. According to the authors' knowlege there are no published reports on determination of studied compounds in pharmaceutical gel formulations. Thus, the aim of this paper is to develop a specific, precise, and accurate chromatographic method that could be applied in quality control for the determination of MET in gel formulation in the presence of both preservatives MP and PP.

\footnotetext{
* Author for correspondence: bozhanov.stanislav@gmail.com
}

\section{Experimental}

Chemicals and Reagents. MET, MP, and PP were purchased from Sigma-Aldrich (Germany) as standards. A MET gel containing $0.75 \% \mathrm{w} / \mathrm{w}$ active compound, $0.1 \% \mathrm{w} / \mathrm{w} \mathrm{MP}$, and $0.05 \% w / w$ PP was obtained commercially. Acetonitrile of liquid chromatography (LC) grade were supplied from Merck (Germany). All other chemical reagents were of analytical grade.

Instrumentation and Chromatographic Conditions. Chromatographic separation was performed on modular HPLC system Shimadzu (Japan) equipped with LC-20AD quaternary pump with an autosampler, Shimadzu DGU-20A 5 vacuum degasser, and a Shimadzu SPD-20A UV/VIS detector. The data was recorded using Lab Solutions Software. A LiChrosorb $\mathrm{C}_{18}$, $250 \mathrm{~mm} \times 4.6 \mathrm{~mm}, 5 \mu \mathrm{m}$ column was used as a stationary phase. The components were separated isocratically with a mobile phase consisting of 20 volumes of acetonitrile and 80 volumes of $0.3 \%$ phosphoric acid modified with $0.1 \%$ triethylamine at a flow rate of $1.0 \mathrm{~mL} \mathrm{~min}{ }^{-1}$. The analysis was carried out at an ambient temperature, and injection volume was $20 \mu \mathrm{L}$. The UV detector was set at $260 \mathrm{~nm}$.

\section{Preparation of Reference Solutions}

Reference solution of MP. Twenty milligrams (accurately weighed) of MP was dissolved in methanol in a $50.0 \mathrm{~mL}$ volumetric flask $\left(C=400 \mu \mathrm{g} \mathrm{mL}^{-1}\right)$.

Reference solution of PP. Twenty milligrams (accurately weighed) of PP was dissolved in methanol in a $100.0 \mathrm{~mL}$ volumetric flask $\left(C=200 \mu \mathrm{g} \mathrm{mL}^{-1}\right)$.

Combined working reference solution. Fifteen milligrams of MET (accurately weighed) was dissolved in methanol in a $100.0 \mathrm{~mL}$ volumetric flask, and $5.0 \mathrm{~mL}$ aliquots of the both parabens reference solutions were added. Finally, the volume was made up to the mark with methanol. Thus, the resulting concentrations of the investigated compounds were as follows: MET, $150 \mu \mathrm{g} \mathrm{mL}^{-1}$; MP, $20 \mu \mathrm{g} \mathrm{mL}^{-1}$; and $\mathrm{PP}, 10 \mu \mathrm{g} \mathrm{mL}^{-1}$, respectively.

Sample Preparation. Two grams (accurately measured) of MET gel corresponding to $15 \mathrm{mg}$ MET, $2 \mathrm{mg} \mathrm{MP}$, and $1 \mathrm{mg}$ PP were transferred to a $20 \mathrm{~mL}$ volumetric flask. Ten

This is an open-access article distributed under the terms of the Creative Commons Attribution-NonCommercial 4.0 International License (https://creativecommons.org/licenses/by-nc/4.0/), which permits unrestricted use, distribution, and reproduction in any medium for non-commercial purposes, provided the original author and source are credited, a link to the CC License is provided, and changes - if any - are indicated. 
milliliters of methanol was added, and the flask was placed in an ultrasonic bath for $20 \mathrm{~min}$. After cooling at room temperature, the flask was filled with methanol to the volume mark. Ten milliliters of the solution was centrifuged at $2000 \mathrm{rpm}$ for $10 \mathrm{~min}$. Five milliliters of the clear centrifugate was transferred to a $25 \mathrm{~mL}$ volumetric flask and filled with mobile phase to the volume mark. After filtration through a $0.45 \mathrm{~mm}$ membrane filter, an aliquot of the sample solution was injected into the HPLC column.

Validation Procedure. The analytical method developed was validated in accordance with International Conference on Harmonization (ICH) guidelines [41].

Selectivity. The ability of an analytical method to unequivocally assess the analyte in the presence of other components can be demonstrated by evaluating specificity. The specificity of the method was evaluated by assessing interference from excipients in the pharmaceutical dosage form prepared as a placebo solution.

Linearity. The linearity of the method was determined at five concentration levels ranging from 37.5 to $300 \mu \mathrm{g} \mathrm{mL}$ for MET, from 5 to $40 \mu \mathrm{g} \mathrm{mL}^{-1}$ for MP, and from 2.5 to $20 \mu \mathrm{g} \mathrm{mL}^{-1}$ for PP. The calibration curves were constructed by plotting peak areas versus concentrations of investigated compounds, and the regression equations were calculated. Each response was the average of three determinations.

Precision. The intra-day precision (repeatability) was determined by triplicate injections of sample at three concentration levels of the tested substances MET, MP, and PP (75:10:5; 150:20:10, and 225:30:15 $\left.\mu \mathrm{g} \mathrm{mL}^{-1}\right)$. The interday precision (reproducibility) was determined by triplicate injections of sample in three different days at the same concentration levels and at the same experimental conditions.

Accuracy. Accuracy of the method was evaluated by standard addition technique, which was performed by addition of known amounts of pure MET and both parabens to known concentrations of gel and analyzed by the proposed method in triplicate. Samples of the gel formulation containing MET, MP, and PP (150:20:10 $\left.\mu \mathrm{g} \mathrm{mL}^{-1}\right)$ were spiked with 50\%, $100 \%$, and $150 \%$ extra MET, MP, and PP standards. Recovery $(\%)$ and relative standard deviation (RSD, \%) were calculated for each concentration.

Detection and Quantification Limits. The limit of detection (LOD) and limit of quantification (LOQ) were defined as the minimum concentration at which the analytes can be detected and quantified, respectively. LOD and LOQ were determined by the signal-to-noise ratio $(S / N 3: 1$ and $S / N$ $10: 1$, respectively).
Stability. The stability of working solutions was checked by reinjection of the samples at the day of experiment and after 24-h storage at room temperature in laboratory conditions.

Robustness. ICH defines the robustness of an analytical procedure as a measure of its capacity to remain unaffected by small but deliberate variations in method parameters. Robustness was determined by changing the flow rate (to 0.8 and $1.2 \mathrm{~mL} \mathrm{~min}^{-1}$ ) and the concentration of acetonitrile in the mobile phase (to $18 \%$ and $22 \%$ ).

\section{Results and Discussion}

In order to achieve optimal chromatographic conditions, several important parameters, such as, percentage and type of organic modifier, $\mathrm{pH}$ of the mobile phase, and concentration of the acid, were studied. Based on our preliminary studies, several mobile phase combinations containing acetonitrile and $o$-phosphoric acid solution with or without addition of triethylamine were tested. The effects of the flow rate of the mobile phase $\left(0.7-1.2 \mathrm{~mL} \mathrm{~min}^{-1}\right)$ and column temperature $\left(25-35^{\circ} \mathrm{C}\right)$ were checked also. Best results regarding resolution, peak shape, and run time were achieved with mobile phase consisting of acetonitrile- $0.3 \%$ phosphoric acid modified with $0.1 \%$ triethylamine $(20: 80 \mathrm{v} / \mathrm{v})$ at a flow rate of $1.0 \mathrm{~mL} \mathrm{~min}^{-1}$, at ambient temperature and optimal wavelenght of $260 \mathrm{~nm}$. The retention times were $3.43 \mathrm{~min}$ for MET, $5.17 \mathrm{~min}$ for PP, and $15.12 \mathrm{~min}$ for MP.

\section{Validation of the Method}

Selectivity. From chromatogram (Figure 1) of placebo, it can be seen that excipients did not interfere with the analytes. Figure 2 shows that, under the experimental chromatographic conditions, MET, PP, and MP were completely separated from each other. There is a peak with retention time of $3.088 \mathrm{~min}$ which is eluted very close to the peak from MET. It can be assumed that it is due to unknown impurity presented at trace levels; the ratio of respective peak areas was 1:350. However, it is sufficiently separated from MET. The respective resolution and selectivity factors were 1.92 and 1.63. Figure 3 shows a zoomed part of Figure 2 in regard to peak with a retention time of $3.088 \mathrm{~min}$ and peak for MET. This indicated that the method is selective and can be used for identification and simultaneous quantification of MET and both preservatives in gel formulation.

The chromatographic parameters for MET and both parabens determined under optimal conditions were satisfactory (tailing factor, $<1$; theoretical plates per column, $>2000$;

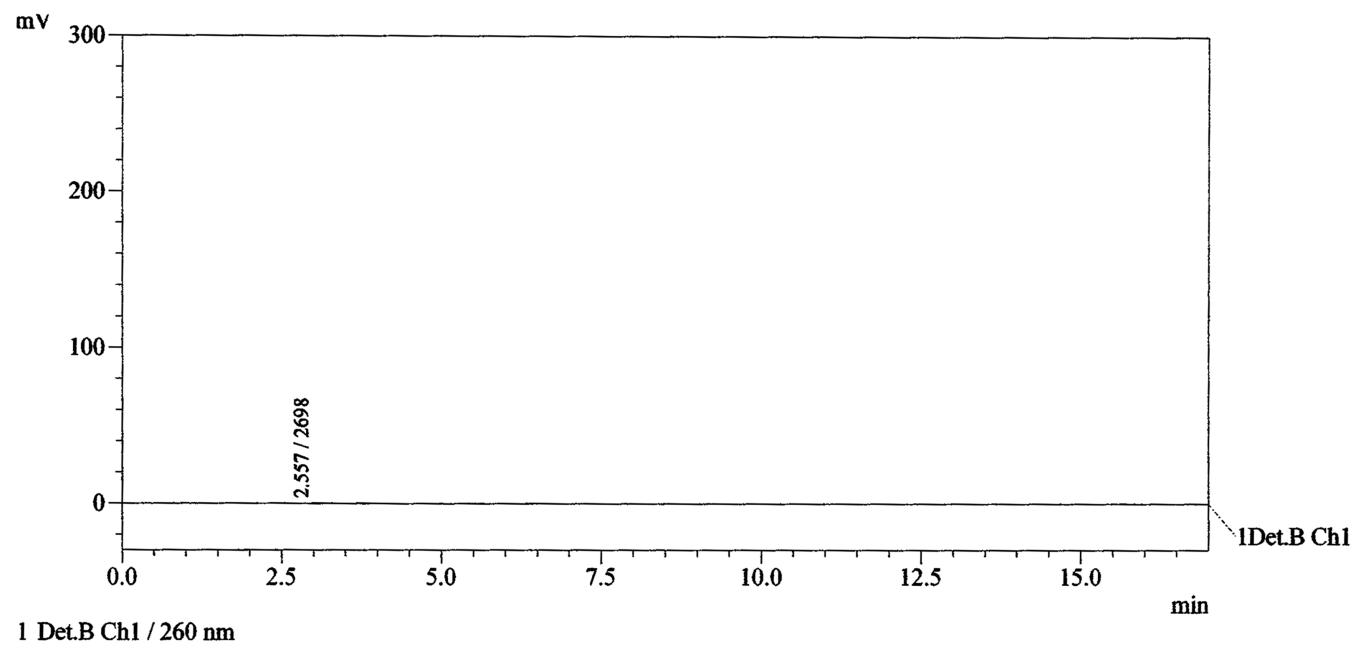

Figure 1. Chromatogram of placebo 


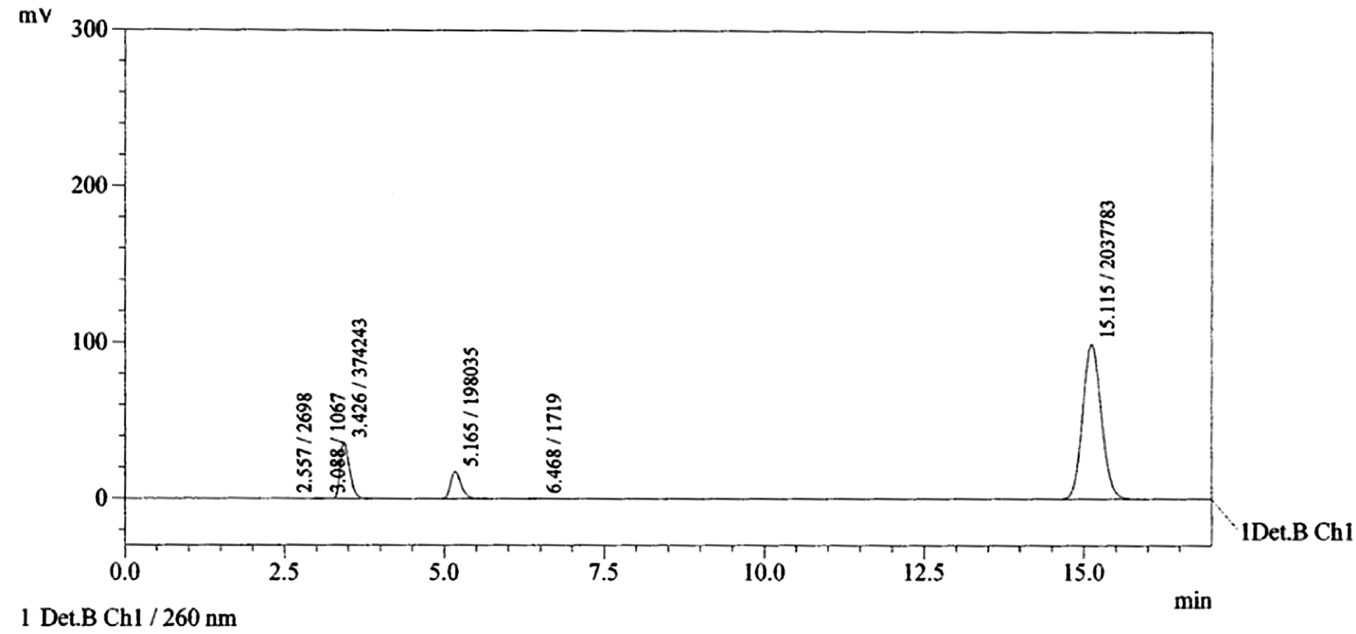

Figure 2. Typical chromatogram of MET, PP and MP

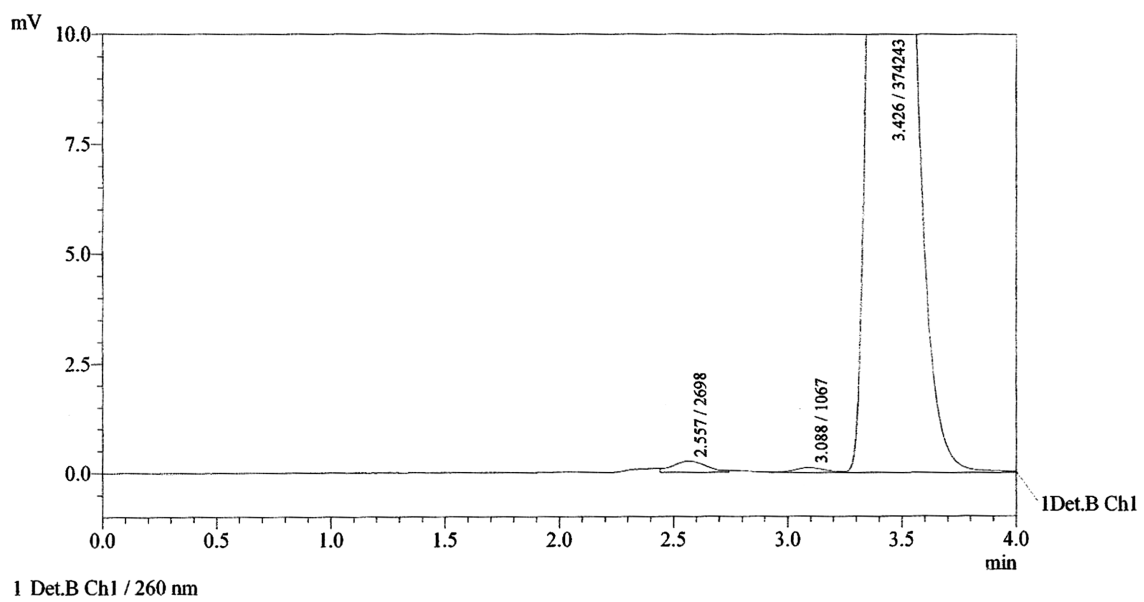

Figure 3. A zoomed part of Figure 2 in regard to peak with retention time 3.088 min and peak for MET

selectivity factor, 1.86-3.21; resolution factor, $>2$; retention factor, 1.83-4.91).

The retention times and chromatographic parameters for MET, PP, and MP obtained by using of the HPLC method are listed in Table 1.

Calibration and Linearity. We prepared a series of 5 calibration solutions with a concentration range shown in Table 2. It was found that response (peak area) was proportional to concentration over the ranges tested with correlation coefficients greater than 0.9998. Calibration plot data slope $(a)$, intercept $(b)$, and correlation coefficient $(r)$ are listed in Table 2.

Precision. The values of \% RSD (Table 3) for MET, MP, and PP were found to be in the range from $0.34 \%$ to $0.97 \%$, indicating good repeatability and reproducibility of the analytical procedure.

Accuracy. The recovery of the method, determined by spiking a previously analyzed test solution with additional drug standards solution, was 99.07-101.0\%. RSD for all analytes was within the range of $0.62-1.58 \%$. The values of recovery

Table 1. Chromatographic data for HPLC method (system-suitability test)

\begin{tabular}{lccc}
\hline \multicolumn{1}{c}{ Parameter } & MET & PP & MP \\
\hline Retention time (min) & 3.43 & 5.17 & 15.12 \\
Tailing factor & 0.95 & 0.93 & 0.95 \\
Theoretical plates & 2360 & 4458 & 12,415 \\
Selectivity factor & 1.86 & 3.01 & 3.21 \\
Resolution factor & 2.03 & 5.88 & 18.26 \\
Retention factor & 1.83 & 2.10 & 4.91 \\
\hline
\end{tabular}

Table 2. Validation data for the calibration plots

\begin{tabular}{lccc}
\hline \multicolumn{1}{c}{ Compounds } & MET & PP & MP \\
\hline Concentration range $\left(\mu \mathrm{g} \mathrm{mL}^{-1}\right)$ & $37.5-300$ & $2.5-20$ & $5-40$ \\
Slope & $21,452.8$ & $34,152.7$ & $48,562.4$ \\
Intercept & 1672.4 & -978.4 & 7425.1 \\
Correlation coefficient $(r)$ & 0.9998 & 0.9999 & 0.9998 \\
\hline
\end{tabular}

Table 3. Precision of the method

\begin{tabular}{|c|c|c|c|c|c|c|c|c|c|}
\hline \multirow[t]{2}{*}{ Precision } & \multicolumn{3}{|c|}{ Amount taken $\left(\mu \mathrm{g} \mathrm{mL}^{-1}\right)$} & \multicolumn{3}{|c|}{$\% \operatorname{Mean}^{a}$} & \multicolumn{3}{|c|}{$\%$ RSD } \\
\hline & MET & MP & PP & MET & MP & PP & MET & MP & PP \\
\hline \multirow[t]{3}{*}{ Intra-day } & 75 & 10 & 5 & 99.46 & 100.3 & 99.52 & 0.34 & 0.48 & 0.78 \\
\hline & 150 & 20 & 10 & 100.4 & 100.1 & 100.1 & 0.62 & 0.63 & 0.65 \\
\hline & 225 & 30 & 15 & 98.65 & 99.48 & 98.73 & 0.35 & 0.51 & 0.71 \\
\hline \multirow[t]{3}{*}{ Inter-day } & 75 & 10 & 5 & 99.78 & 99.82 & 99.81 & 0.81 & 0.68 & 0.47 \\
\hline & 150 & 20 & 10 & 99.61 & 99.54 & 99.62 & 0.79 & 0.97 & 0.43 \\
\hline & 225 & 30 & 15 & 99.65 & 98.18 & 98.93 & 0.78 & 0.96 & 0.45 \\
\hline
\end{tabular}

${ }^{a}$ Mean of three determinations.

(\%) and RSD (\%) presented in Table 4 indicated good accuracy and showed no interference from excipients; hence, the proposed method is suitable for the quantitative determination of MET, MP, and PP.

Limit of Detection and Limit of Quantification. LOQ and LOD were evaluated based on signal-to-noise ratios by serial dilution of working reference solution. The LOQs for MET, $\mathrm{MP}$, and PP were found to be $1.0,0.8$, and $0.5 \mu \mathrm{g} \mathrm{mL}^{-1}$ respectively, and the LODs were $0.2,0.1$, and $0.05 \mu \mathrm{g} \mathrm{mL}^{-1}$, respectively. 
Table 4. Recovery studies of MET and parabens

\begin{tabular}{|c|c|c|c|c|c|}
\hline Compound & $\begin{array}{l}\text { Amount (\%) of drug } \\
\text { added to analyte }\end{array}$ & $\begin{array}{l}\text { Amount taken } \\
\left(\mu \mathrm{g} \mathrm{mL} L^{-1}\right)\end{array}$ & $\begin{array}{l}\text { Amount found } \\
\left(\mu \mathrm{g} \mathrm{mL}^{-1}\right)\end{array}$ & $\begin{array}{c}\text { Amount recovered } \pm \mathrm{SD}^{a} \\
(\%)\end{array}$ & $\%$ RSD \\
\hline \multirow[t]{3}{*}{$\overline{\mathrm{MET}}$} & 50 & 75 & 74.50 & $99.33 \pm 1.15$ & 0.62 \\
\hline & 100 & 150 & 149.2 & $99.47 \pm 1.52$ & 0.68 \\
\hline & 150 & 225 & 224.5 & $99.78 \pm 1.68$ & 0.64 \\
\hline \multirow[t]{3}{*}{ MP } & 50 & 10 & 10.06 & $100.6 \pm 0.52$ & 1.10 \\
\hline & 100 & 20 & 20.21 & $101.0 \pm 0.47$ & 1.58 \\
\hline & 150 & 30 & 29.64 & $98.85 \pm 0.36$ & 1.00 \\
\hline \multirow[t]{3}{*}{ PP } & 50 & 5 & 4.94 & $98.81 \pm 0.22$ & 1.77 \\
\hline & 100 & 10 & 9.98 & $99.80 \pm 0.21$ & 1.32 \\
\hline & 150 & 15 & 14.86 & $99.07 \pm 0.15$ & 0.82 \\
\hline $\begin{array}{l}{ }^{a} \text { Avera } \\
\text { RSD is }\end{array}$ & $\begin{array}{l}\text { ee determinations. } \\
\text { ard deviation. }\end{array}$ & & & & \\
\hline
\end{tabular}

Stability. It was found that the prepared samples are stable for $24 \mathrm{~h}$, which was sufficient to perform and complete all measurements. No significant differences in analytes behavior were found.

Robustness. No significant differences was found in the retention time of MET and both parabens when the composition and flow rate of the mobile phase were changed.

\section{Conclusion}

The validated reversed-phase (RP)-LC method developed here proved to be simple, specific, accurate, precise, and sensitive. It can successfully be used for routine analysis of MET in the presence of described preservatives in gel formulation without any interference from common excipients.

Acknowledgment. The present study was kindly supported by Medical University of Sofia, Medical Science Council (Project No. 34/2015).

\section{References}

1. Sobel, J. D.; Ferris, D.; Schwebke, J.; Nyirjesy, P.; Wiesenfeld, H. C.; Peipert, J.; Soper, D.; Ohmit, S. E.; Hiller, S. L. Am. J. Obstet. Gynecol. 2006, 194, 1283.

2. Hope, M. J.; Kitson, C. N. Dermatol. Clin. 1993, 11, 143.

3. Mishra, A. K.; Yadava, R.; Mishra, A.; Verma, A.; Chattopadhyay, P. Int. J. Pharma. Res. Dev. 2010, 2, 1.

4. Rehman, A.; Ijaz, A. S.; Raza, A. J. Iran. Chem. Soc. 2005 2, 197.

5. Miljkovic, V. M.; Kostic, D. A.; Bojanic, Z. Z.; Kalicanin, B. M.; Kocic, G. M. Tropical J. Pharm. Res. 2014, 13, 417.

6. Siddappa, K.; Mallikarjun, M.; Reddy, P. T.; Tambe, M. Ecl. Quim. 2008, 33, 41 .

7. Simoes, S.; Medeiros, E.; Gaviao, E.; Lyra, W.; Moreira, P.; Araujo,

M.; Silva, E.; Nascimento, V. J. Braz. Chem. Soc. 2006, 17, 609.

8. Adegoke, O. A.; Umoh, O. E. Acta. Pharm. 2009, 59, 407.

9. Nandini, P.; Deeptanshu, A. Der Pharm. Sin. 2014, 5, 23.

10. Verma, P.; Namboodiry, V.; Mishra, S.; Bhagwat, A.; Bhoir, S. Int. J. Pharm. Pharm. Sci. 2013, 5, 496.

11. Hassan, S.; Hussain, S.; Ansari, M. T. Pakistan J. Zool. 2011, 43, 909.

12. Tashtoush, B. M.; Jacobson, E. L.; Jacobson, M. K. Drug Dev. Ind. Pharm. 2008, 34, 840 .
13. Jin, W.; Li, W.; Xu, Q.; Dong, Q. Electrophoresis 2000, 21, 1409.

14. Palomeque, M.; Bautista, J. A. G.; Mateo, J. V. G.; Calatayud, J. M. Anal. Chim. Acta 1999, 401, 229.

15. Barlett, P. N.; Ghoneim, E.; El-Hefnawy, G.; El-Hallag, I. Talanto 2005, 66, 869.

16. Chen, D.; Deng, J.; Liang, J.; Xie, J.; Hu, C.; Huang, K. Sens. Actuators B Chem. 2013, 183, 594.

17. Mollamahale, Y. B.; Ghorbani, M.; Ghalkhani, M.; Vossoughi, M.; Dolati, A. Electrochim. Acta 2013, 106, 288.

18. Yang, G.; Zhao, F.; Zeng, B. Electrochim. Acta 2014 135, 154.

19. Peng, J.; Hou, C.; Hu, X. Sens. Actuators B Chem. 2012, 169, 81

20. El-Sayed, G. O. Microchem. J. 1997, 55, 110.

21. Papas, A. N.; Delaney, M. F. Anal. Lett. 1982 15, 739.

316.

23. Rezaei, B ; Damiri, S. Electrochim. Acta 2010, 55, 1801

24. Lu, S.; Wu, K.; Dang, X.; Hu, S. Talanta 2004, 63, 653.

25. Brett, A. M. O.; Serrano, S. H. P.; Gutz, I.; La-Scalea, M. A. Bioelectroch. Bioener. 1997, 42, 175.

26. Yao, Z.; Jingbo, H.; Zhongda, W.; Qilong, L. Anal. Lett. 1998, 31, 429.

27. Gholivand, M. B.; Torkashvand, M. Talanta 2011, 84, 905.

28. Chen, H.; Zhang, Z.; Cai, R.; Kong, X.; Chen, X.; Liu, Y.; Yao, S. Analyst 2013, 138, 2769.

29. Liu, W.; Zhang, J.; Li, C.; Tang, L.; Zhang, Z.; Yang, M. Talanta 2013 104, 204.

30. Ozkan, S. A.; Ozkan, Y.; Senturk, Z. J. Pharm. Biomed. Anal. 1998, 17,299

31. Yilmaz, S.; Baltaoglu, E.; Saglikoglu, G.; Yagmur, S.; Polat, K.; Sadikoglu, M. J. Serb. Chem. Soc. 2013, 78, 295.

32. Błędzka, D.; Gromadzińska, J.; Wąsowicz, W. Environ. Int. 2014, 67, 27.

33. Ali, M. S.; Ghori, M.; Khatri, A. R. J. Pharm. Biomed. Anal. 2006, 41, 358.

34. Matysova, L.; Hajkova, R.; Sicha, J.; Solich, P. Anal. Bioanal. Chem. 2003, 376, 440 .

35. Dvořák, J.; Hájková, R.; Matysová, L.; Nováková, L.; Koupparis, M. A.; Solich, P. J. Pharm. Biomed. Anal. 2004, 36, 625.

36. Labbozzetta, S.; Valvo, L.; Bertocchi, P.; Alimonti, S.; Gaudiano, M.

C.; Manna, L. Chromatographia 2009, 69, 365

37. Blanco, M.; Coello, J.; Iturriaga, H.; Maspoch, S.; Alaoui-Ismaili, S. Fresenius J. Anal. Chem. 1997, 357, 967.

38. Safra, J.; Pospisilova, M. J. Pharm. Biomed. Anal. 2008, 48, 452.

39. Ali, M. S.; Chaudhary, R. S.; Takieddin, M. A. Drug Dev. Ind. Pharm. 1999, 25, 1143

40. Pashankov, P.; Kostova, L. J. Chromatogr. A. 1987, 394, 382.

41. International Conference on Harmonization 2005 ICH harmonized tripartite guideline Validation of analytical procedures: text and methodology Q2 (RI) ICH, Geneva, Nov; 2005. 